\title{
ANALISIS KEBUTUHAN PARKIR B BANDAR UDARA INTERNASIONAL KUALANAMU ( STUDI KASUS KENDARAAN RODA EMPAT )
}

\author{
Tri Rahayu \\ Dosen Pengajar Program Studi Teknik Sipil, Fakultas Teknik, UMSU, Medan \\ Surel : yayuk.asmawi@yahoo.co.id \\ Diterima : 15 November 2017; Disetujui : 22 November 2017
}

\begin{abstract}
ABSTRAK
Kebutuhan akan ruang parkir merupakan hal yang penting dalam pusat kegiatan karena dapat menimbulkan masalah seperti antrian, tundaan atau kemacetan serta akan mengganggu terhadap kelancaran lalu lintas jika ketersediaan kapasitas jalan dan area parkir tidak memadai.Tujuan dari penelitian ini adalah untuk menganalisis kapasitas dan kebutuhan ruang parkir B di Bandar Udara Intenasional Kualanamu Medan. Penelitian yang dilakukan yaitu berupa survey dengan mencatat waktu kendaraan yang masuk dan keluar dari lokasi parkir untuk melihat volume parkir, akumulasi parkir, durasi rata-rata parkir kendaraan, indeks parkir, tingkat pergantian parkir dan kapasitas parkir. Waktu pengamatan dilakukan pada hari minggu sampai hari kamis.Berdasarkan hasil perhitungan, akumulasi parkir tertinggi yaitu 251 kendaraan yang terjadi pada pukul 15.00 - 16.00 WIB dengan indeks parkir 37,74\%, hal ini menunjukkan bahwa satuan ruang parkir (SRP) mobil masih dapat menampung kendaraan yang akan parkir sehingga membuat batasan-batasan parkir sesuai dengan sudut parkir yang di tentukan dan memperbaiki sirkulasi kendaraan yang masuk dan keluar dari lokasi parkir.
\end{abstract}

Kata Kunci : kapasitas parkir, karakteristik parker, Kebutuhan ruang parkir

\begin{abstract}
Parking space requirement is important in the activity because it can be a problem such as queue, delay or congestion will interfere with the smooth traffic if availability of road capacity and inadequate parking area.The goal of this research is to analyze capacity and parking B needs at Internasional Kualanamu Airport Medan. This research are obtained by doing survey to record the time the vehicle entry and exit parking location to see volume parking, accumulation of parking, mean parking duration, parking index, parking turn over and parking capacity. Time observations were made on Sunday and Monday. Based on calculation, accumulated the highest parking of 251 vehicle at 15.00 - 16.00 WIB with parking index $37.74 \%$, it is indicate the unit parking spaces of car can not accomodate vehicles to be parked so the needs for additional parking plots, improvement of road conditions and parking lot, create a progressive parking rates, make parking retrictions with angle parking planned and improve vehicle circulation the entry and exit parking location.
\end{abstract}

Keywords: parking capacity, parking characteristics, Parking space requirements

\section{Pendahuluan}

Kebutuhan akan ruang parkir merupakan hal yang penting dalam pusat kegiatan karena dapat menimbulkan masalah seperti antrian, tundaan atau kemacetan serta akan mengganggu terhadap kelancaran lalu lintas jika ketersediaan kapasitas jalan dan area parkir di tempat tersebut tidak mampu menampung kendaraan yang akan parkir. Permasalahan yang dirumuskan dalam penelitian ini adalah Volume kendaraan yang parkir lebih dari kapasitas parkir B yang tersedia, terutama pada saat jam sibuk, sehingga tidak sesuai dengan pola parkir yang disediakan pengelola parkir B , Survei ini dilakukan selama 5 hari. Dalam penelitian ini 


\section{Tri Rahayu}

diharapkan dapat memberikan gambaran dan kejelasan dari permasalahan fasilitas Parkir B di Bandar Udara Internasional Kualanamu Medan serta mengetahui arti penting penyediaan ruang parkir yang terhadap kebutuhan saat ini.

Pada saat penelitian Waktu pengamatan disesuaikan dengan jam tiba dan pemberangkatan pesawat dari atau menuju rute yang ditentukan dalam jadwal Bandar Udara Internasional Kualanamu Medan, waktu pengamatan dilakukan selama 10 jam. Dan jenis kendaraan yang diamati adalah kendaraan roda empat (mobil pribadi

\section{Kajian Pustaka}

\subsection{Satuan Ruang Parkir (SRP)}

\section{Menurut} Pedoman

Teknis

Penyelenggaraan Fasilitas Parkir (Direktorat Jenderal Perhubungan Darat, 1996) satuan Ruang Parkir (SRP) adalah luas efektif untuk memarkir satu kendaraan (mobil penumpang, truk, motor) termasuk ruang bebas dan lebar bukaan pintu.

Untuk menentukan SRP didasarkan pada hal berikut:

a. Dimensi Kendaraan Standar

Dimensi Kendaraan Standar untuk mobi penumpang adalah $5,0 \mathrm{~m} \quad \mathrm{x} 2,5 \mathrm{~m}$ sedangkan untuk sepeda motor adalah 0,7 $\mathrm{m} \times 1,75 \mathrm{~m}$.

b. Ruang Bebas Kendaraan Parkir

Ruang bebas kendaraan parkir diberikan pada arah lateral dan longitudinal atau memanjang kendaraan. Ruang arah lateral diterapkan pada saat posisi pintu kendaraan dibuka, yang diukur dari ujung paling luar ke badan kendaraan parkir yang ada di sampingnya. Ruang bebas ini diberikan agar tidak terjadi benturan antara pintu kendaraan dan kendaraan yang parkir di sampingnya pada saat penumpang turun dari kendaraan. Ruang bebas arah memanjang diberikan di depan kendaraan untuk menghindari benturan dengan dinding atau kendaraan yang lewat jalur gang (aisle). Jarak bebas arah lateral diambil sebesar $5 \mathrm{~cm}$ dan jarak bebas arah memanjang sebesar $30 \mathrm{~cm}$.

Penentuan satuan ruang parkir (SRP) dibagi atas tiga jenis kendaraan seperti pada tabel berikut :
Tabel 1. Penentuan Satuan Ruang Parkir (SRP) (sumber Direktorat Jendral Perhubungan Darat, 1996)

\begin{tabular}{lc}
\hline Jenis Kendaraan & $\begin{array}{l}\text { Satuan } \\
\text { Parkir }\left(\mathbf{m}^{2}\right)\end{array}$ \\
\hline $\begin{array}{l}\text { Mobil Penumpang } \\
\text { Gol I }\end{array}$ & $2,3 \times 5,0$ \\
\hline $\begin{array}{l}\text { Mobil Penumpang } \\
\text { Gol II }\end{array}$ & $2,5 \times 5,0$ \\
\hline $\begin{array}{l}\text { Mobil Penumpang } \\
\text { Gol III }\end{array}$ & $3,0 \times 5,0$ \\
\hline Bus dan Truck & $3,4 \times 12,5$ \\
\hline Sepeda Motor & $0,75 \times 2,0$ \\
\hline
\end{tabular}

Tabel 2. Ukuran Satuan Ruang Parkir Mobil Penumpang (dalam meter) (sumber Direktorat Jendral Perhubungan Darat, 1996)

\begin{tabular}{llll}
\hline GOL. I & $\mathrm{B}=1,70$ & $\mathrm{a}_{1}=0,10$ & $\begin{array}{l}\mathrm{Bp}= \\
\mathrm{B}+\mathrm{O}+\mathrm{R}\end{array}$ \\
\cline { 2 - 4 } & $\mathrm{O}=0,55$ & $\mathrm{~L}=4,70$ & $\begin{array}{l}\mathrm{Lp}=\mathrm{L}+\mathrm{a} 1 \\
+\mathrm{a} 2\end{array}$ \\
\cline { 2 - 4 } & $\mathrm{R}=0,05$ & $\mathrm{a}_{2}=0,20$ & $\begin{array}{l}\mathrm{Bp}=2,30 \\
\mathrm{Lp}=5,0\end{array}$ \\
\hline GOL.II & $\mathrm{B}=1,70$ & $\mathrm{a}_{1}=0,10$ & \\
\cline { 2 - 4 } & $\mathrm{O}=0,75$ & $\mathrm{~L}=4,70$ & \\
\cline { 2 - 4 } & $\mathrm{R}=0,05$ & $\mathrm{a}_{2}=0,20$ & $\mathrm{Bp}=2,50$ \\
& & & $\mathrm{Lp}=5,0$ \\
\hline GOL.III & $\mathrm{B}=1,70$ & $\mathrm{a}_{1}=0,10$ & \\
\cline { 2 - 4 } & $\mathrm{O}=0,80$ & $\mathrm{~L}=4,70$ & \\
\cline { 2 - 4 } & $\mathrm{R}=0,05$ & $\mathrm{a}_{2}=0,20$ & $\mathrm{Bp}=3,0$ \\
$\mathrm{Lp}=5,0$
\end{tabular}

Tabel 3. Ukuran Satuan Ruang Parkir Bus dan Truck (dalam meter) (sumber Direktorat Jendral Perhubungan Darat, 1996)

\begin{tabular}{llll}
\hline GOL. I & $\mathrm{B}=1,70$ & $\mathrm{a}_{1}=0,10$ & $\begin{array}{l}\mathrm{Bp}= \\
\mathrm{B}+\mathrm{O}+\mathrm{R}\end{array}$ \\
\cline { 2 - 4 } & $\mathrm{O}=0,80$ & $\mathrm{~L}=4,70$ & $\begin{array}{l}\mathrm{Lp}=\mathrm{L}+\mathrm{a} 1 \\
+\mathrm{a} 2\end{array}$ \\
\cline { 2 - 4 } & $\mathrm{R}=0,30$ & $\mathrm{a}_{2}=0,20$ & $\begin{array}{l}\mathrm{Bp}=2,80 \\
\mathrm{Lp}=5,0\end{array}$ \\
\hline GOL.II & $\mathrm{B}=2,00$ & $\mathrm{a}_{1}=0,20$ & \\
\cline { 2 - 4 } & $\mathrm{O}=0,80$ & $\mathrm{~L}=8,00$ \\
\cline { 2 - 4 } & $\mathrm{R}=0,40$ & $\mathrm{a}_{2}=0,20$ & $\mathrm{Bp}=3,20$ \\
& & & $\mathrm{Lp}=8,40$ \\
\hline GOL.III & $\mathrm{B}=2,50$ & $\mathrm{a}_{1}=0,30$ & \\
\cline { 2 - 4 } & $\mathrm{O}=0,80$ & $\mathrm{~L}=12,00$ & \\
\cline { 2 - 4 } & $\mathrm{R}=0,50$ & $\mathrm{a}_{2}=0,20$ & $\mathrm{Bp}=3,80$ \\
& & & $\mathrm{Lp}=12,50$ \\
\hline
\end{tabular}

2.2 Lay out Parkir Kendaraan dan Jadwal Penerbangan

a. Lay out Parkir kendaraan

Berdasarkan Lay Out parkir Kendaraan pada Bandar Udara Internasional Kualanamu 


\section{Analisis Kebutuhan Parkir B Bandar Udara Internasional Kualanamu (Studi Kasus Kendaraan Roda Empat)}

Medan Lokasi Parkir B terdiri dari lokasi parkir kendaraan bermobil.

Untuk lokasi parkir kendaraan bermobil terdiri dari satu denah parkir yaitu zona parkir B untuk kendaraan mobil pribadi, /taxi/travel sebagia pengantar dan penjemput penumpang dan ruangan VIP yang dikhusukan sebagai tempat parkir pengantar dan penjemput pejabat negara.

\section{b. Jadwal Penerbangan}

Jadwal penerbangan yang termasuk jadwal kedatangan dan keberangkatan pesawat dapat mempengaruhi kapasitas parkir yang di butuhkan pada suatu lokasi parkir. RON (Remain Over Night) merupakan waktu dimana tidak adanya jadwal penerbangan sehingga pesawat tinggal di bandara untuk bermalam.

Tabel 4. Jadwal kegiatan waktu tiba dan berangkat pesawat dalam 1 minggu pada Bandar Udara Internasional Kualanamu Medan tahun 2017. (sumber Direktorat Jendral Perhubungan Darat, 1996)

\begin{tabular}{|c|c|c|c|c|}
\hline \multirow[t]{2}{*}{ NO } & \multirow{2}{*}{$\begin{array}{l}\text { Nama } \\
\text { Pesawat }\end{array}$} & \multicolumn{2}{|c|}{ Jam Penerbangan } & \multirow[t]{2}{*}{ Hari } \\
\hline & & Tiba & Berangkat & \\
\hline 1 & Lion Air & RON & 6.30 & $\begin{array}{l}\text { Setiap } \\
\text { Hari }\end{array}$ \\
\hline 2 & $\begin{array}{l}\text { Garuda } \\
\text { Indonesia }\end{array}$ & 6.30 & 7.15 & $\begin{array}{l}\text { Setiap } \\
\text { Hari }\end{array}$ \\
\hline 3 & $\begin{array}{l}\text { Sriwijaya } \\
\text { Air }\end{array}$ & 7.40 & 8.10 & $\begin{array}{l}\text { Setiap } \\
\text { Hari }\end{array}$ \\
\hline 4 & $\begin{array}{l}\text { Garuda } \\
\text { Indonesia }\end{array}$ & 10.00 & 10.45 & $\begin{array}{l}\text { Setiap } \\
\text { Hari }\end{array}$ \\
\hline 5 & $\begin{array}{l}\text { Sriwijaya } \\
\text { Air } \\
\end{array}$ & 10.30 & 11.00 & $\begin{array}{l}\text { Setiap } \\
\text { Hari }\end{array}$ \\
\hline 6 & $\begin{array}{l}\text { Sriwijaya } \\
\text { Air }\end{array}$ & 12.48 & 13.15 & $\begin{array}{l}\text { Setiap } \\
\text { Hari }\end{array}$ \\
\hline 7 & $\begin{array}{l}\text { Garuda } \\
\text { Indonesia }\end{array}$ & 12.55 & 13.35 & $\begin{array}{l}\text { Setiap } \\
\text { Hari }\end{array}$ \\
\hline 8 & $\begin{array}{l}\text { Garuda } \\
\text { Indonesia }\end{array}$ & 13.35 & 14.20 & $\begin{array}{l}\text { Setiap } \\
\text { Hari }\end{array}$ \\
\hline 9 & $\begin{array}{l}\text { Sriwijaya } \\
\text { Air }\end{array}$ & 14.15 & 14.45 & $\begin{array}{l}\text { Setiap } \\
\text { Hari }\end{array}$ \\
\hline 10 & $\begin{array}{l}\text { Sriwijaya } \\
\text { Air } \\
\end{array}$ & 16.15 & 16.45 & $\begin{array}{l}\text { Setiap } \\
\text { Hari } \\
\end{array}$ \\
\hline 11 & $\begin{array}{l}\text { Garuda } \\
\text { Indonesia }\end{array}$ & 16.20 & 17.05 & $\begin{array}{l}\text { Setiap } \\
\text { Hari }\end{array}$ \\
\hline 12 & $\begin{array}{l}\text { Garuda } \\
\text { Indonesia }\end{array}$ & 17.50 & 18.35 & $\begin{array}{l}\text { Setiap } \\
\text { Hari } \\
\end{array}$ \\
\hline 13 & $\begin{array}{l}\text { Sriwijaya } \\
\text { Air } \\
\end{array}$ & 17.55 & 18.30 & $\begin{array}{l}\text { Setiap } \\
\text { Hari }\end{array}$ \\
\hline 14 & $\begin{array}{l}\text { Sriwijaya } \\
\text { Air }\end{array}$ & 18.10 & 18.40 & $\begin{array}{l}\text { Setiap } \\
\text { Hari }\end{array}$ \\
\hline 15 & Lion Air & 20.15 & RON & $\begin{array}{l}\text { Setiap } \\
\text { Hari }\end{array}$ \\
\hline
\end{tabular}

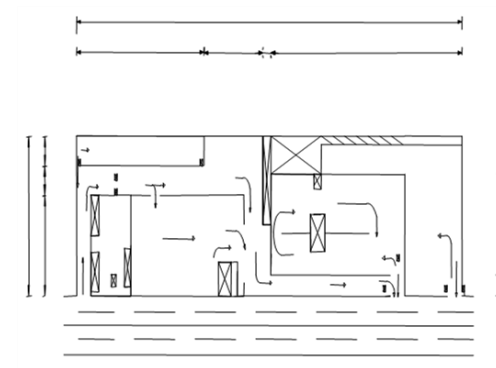

Gambar 1. Lay Out parkir Bandar B Udara Internasional Kualanamu, Sumber : Hasil Survey

Ket :

b.1 = Pintu keluar kendaraan bermobil

b. 3 = Pintu keluar kendaraan bermobil pada ruangan VIP

\section{Hasil dan Pembahasan}

\subsection{Luas Areal Parkir}

Luas areal parkir yang tersedia diperoleh dari database PT. Angkasa Pura I (Persero). Data luas parkir untuk kendaraan roda empat sebesar $50.420 \mathrm{~m}^{2}$ dengan jumlah petak parkir sebanyak 454 petak. Sketsa areal parkir dapat dilihat pada lampiran.

\subsection{Volume Parkir Kendaraan Masuk dan Keluar}

Tabel 5. Volume Parkir B Kendaran Masuk Roda Empat Hari ini

\begin{tabular}{cc}
\hline $\begin{array}{c}\text { Waktu } \\
\text { (Minggu) }\end{array}$ & $\begin{array}{c}\text { Vol, Maks } \\
\text { (Kendaraan Masuk) }\end{array}$ \\
\hline $07.00-08.00$ & 214 \\
\hline $12.00-13.00$ & 236 \\
\hline $15.00-16.00$ & 251 \\
\hline & \\
\hline Waktu & $\begin{array}{c}\text { Vol, Maks } \\
\text { (senin) }\end{array}$ \\
\hline $07.00-08.00$ & 146 \\
\hline $12.00-13.00$ & 212 \\
\hline $15.00-16.00$ & 234 \\
\hline
\end{tabular}

\begin{tabular}{cc}
\hline $\begin{array}{c}\text { Waktu } \\
\text { (selasa) }\end{array}$ & $\begin{array}{c}\text { Vol, Maks } \\
\text { (Kendaraan Masuk) }\end{array}$ \\
\hline $07.00-08.00$ & 167 \\
\hline $12.00-13.00$ & 198 \\
\hline $15.00-16.00$ & 232 \\
\hline
\end{tabular}

\begin{tabular}{cc}
\hline $\begin{array}{c}\text { Waktu } \\
\text { (rabu) }\end{array}$ & $\begin{array}{c}\text { Vol, Maks } \\
\text { (Kendaraan Masuk) }\end{array}$ \\
\hline $07.00-08.00$ & 184 \\
\hline $12.00-13.00$ & 162 \\
\hline $15.00-16.00$ & 193 \\
\hline
\end{tabular}




\section{Tri Rahayu}

\begin{tabular}{cc}
\hline $\begin{array}{c}\text { Waktu } \\
\text { (kamis) }\end{array}$ & $\begin{array}{c}\text { Vol, Maks } \\
\text { (Kendaraan Masuk) }\end{array}$ \\
\hline $07.00-08.00$ & 147 \\
\hline $12.00-13.00$ & 156 \\
\hline $15.00-16.00$ & 187 \\
\hline
\end{tabular}

Berdasarkan tabel diatas diperoleh volume maksimum kendaraan masuk roda empat terjadi pada hari minggu dengan jumlah volume 251 kendaraan, sedangkan volume maksimum pada hari senin dengan jumlah volume 234 kendaraan.

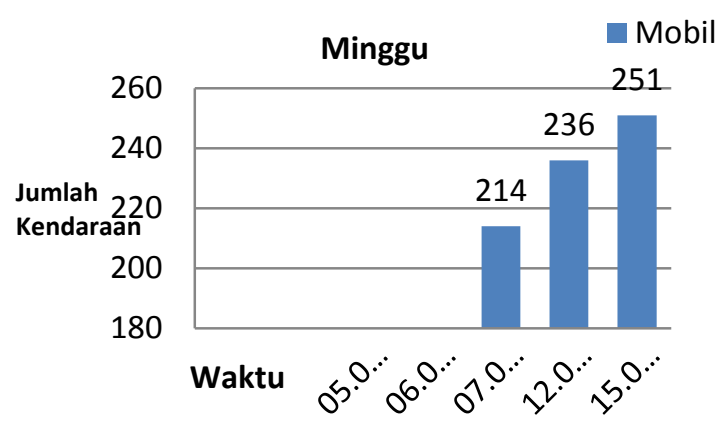

Gambar 2 Volume Parkir Kendaraan Masuk pada hari Minggu, Sumber : Hasil Survey

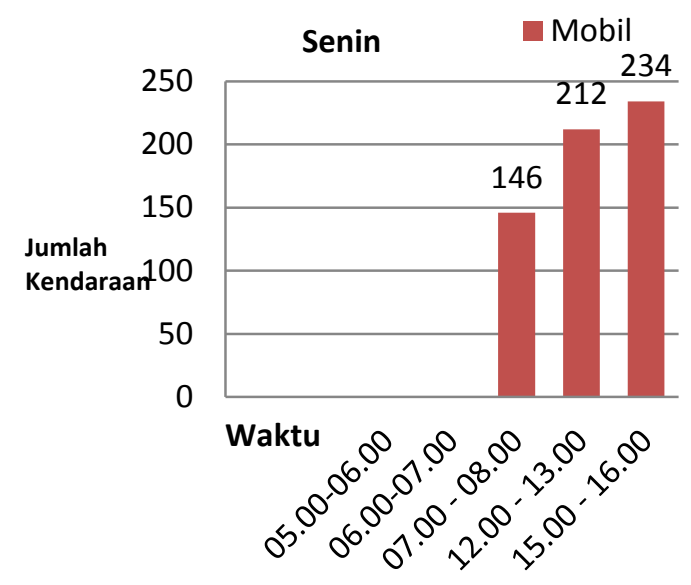

Gambar 3 Volume Parkir Kendaraan Masuk pada hari senin, Sumber : Hasil Survey

Untuk volume parker keluar mobil pada Bandar Udara Internasional Kualanamu Medan dapat dilihat pada Tabel sebagai berikut

Tabel 6. Volume Parkir B Kendaran keluar Roda Empat Hari ini

\begin{tabular}{cc}
\hline $\begin{array}{c}\text { Waktu } \\
\text { (Minggu) }\end{array}$ & $\begin{array}{c}\text { Vol, Maks } \\
\text { (Kendaraan keluar) }\end{array}$ \\
\hline $07.00-08.00$ & 107 \\
\hline $12.00-13.00$ & 118 \\
\hline $15.00-16.00$ & 125 \\
\hline
\end{tabular}

\begin{tabular}{cc}
\hline $\begin{array}{c}\text { Waktu } \\
\text { (senin) }\end{array}$ & $\begin{array}{c}\text { Vol, Maks } \\
\text { (Kendaraan keluar) }\end{array}$ \\
\hline $07.00-08.00$ & 73 \\
\hline $12.00-13.00$ & 106 \\
\hline $15.00-16.00$ & 117 \\
\hline & \\
\hline $\begin{array}{c}\text { Waktu } \\
\text { (selasa) }\end{array}$ & $\begin{array}{c}\text { Vol, Maks } \\
\text { (Kendaraan keluar) }\end{array}$ \\
\hline $07.00-08.00$ & 73 \\
\hline $12.00-13.00$ & 106 \\
\hline $15.00-16.00$ & 117 \\
\hline
\end{tabular}

\begin{tabular}{cc}
\hline $\begin{array}{c}\text { Waktu } \\
\text { (rabu) }\end{array}$ & $\begin{array}{c}\text { Vol, Maks } \\
\text { (Kendaraan keluar) }\end{array}$ \\
\hline $07.00-08.00$ & 73 \\
\hline $12.00-13.00$ & 106 \\
\hline $15.00-16.00$ & 117 \\
\hline
\end{tabular}

\begin{tabular}{cc}
\hline $\begin{array}{c}\text { Waktu } \\
\text { (kamis) }\end{array}$ & $\begin{array}{c}\text { Vol, Maks } \\
\text { (Kendaraan keluar) }\end{array}$ \\
\hline $07.00-08.00$ & 73 \\
\hline $12.00-13.00$ & 106 \\
\hline $15.00-16.00$ & 117 \\
\hline
\end{tabular}

Berdasarkan tabel diatas diperoleh volume maksimum parkir B kendaraan keluar roda empat terjadi pada hari Minggu dengan jumlah volume 125 kendaraan, sedangkan volume maksimum pada hari Senin dengan jumlah 117 kendaraan.

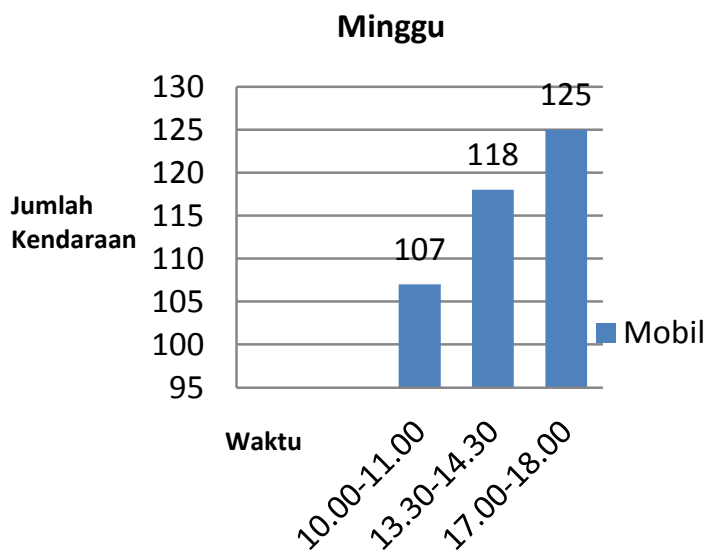

Gambar 4 Volume Parkir Kendaraan keluar pada hari minggu, Sumber : Hasil Survey 


\section{Analisis Kebutuhan Parkir B Bandar Udara Internasional Kualanamu (Studi Kasus Kendaraan Roda Empat)}

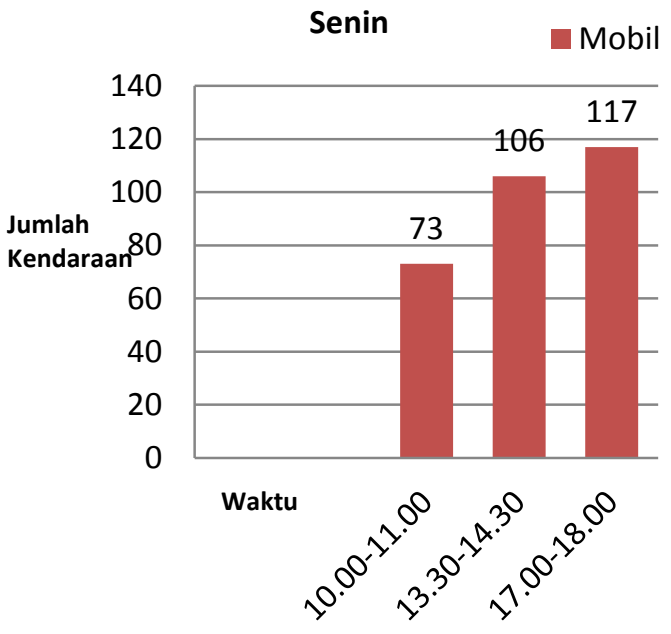

Gambar 5 Volume Parkir Kendaraan keluar pada hari senin, Sumber : Hasil Survey

\subsection{Akumulasi Keluar}

Berdasarkan hasil pengolahan data, maka diperoleh Akumulasi maksimum kendaraan parkir untuk kendaraan roda empat pada Bandar Udara Internasional Kualanamu Medan, dapat dilihat pada Gambar sebagai berikut :

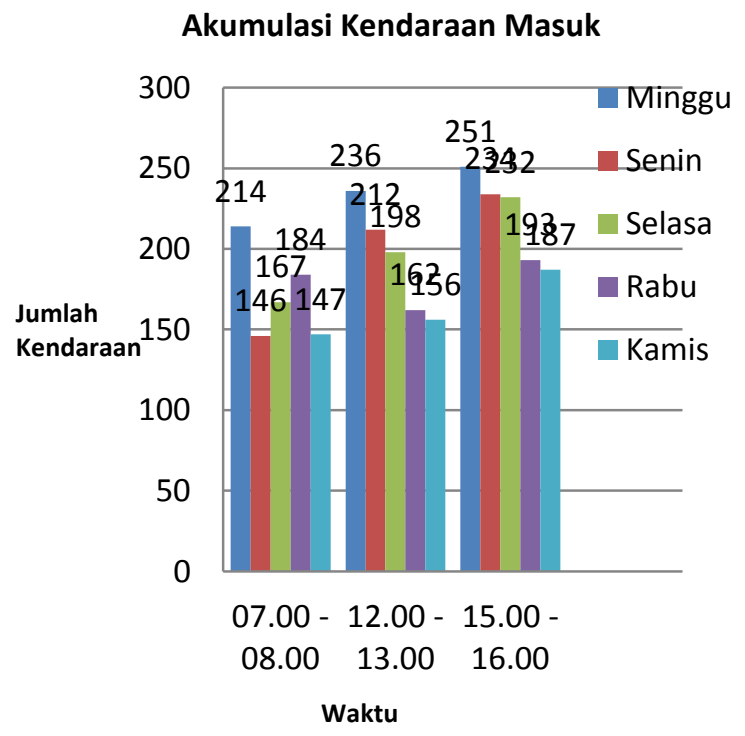

Gambar 6 Akumulasi Kendaraan Masuk Roda Empat, Sumber : Hasil Survey

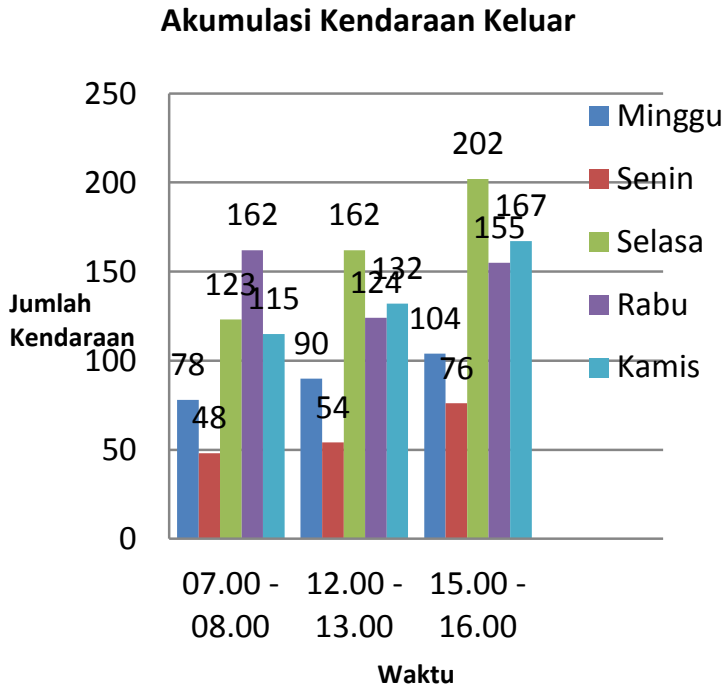

Gambar 6 Akumulasi Kendaraan Keluar Roda Empat, Sumber : Hasil Survey

\section{Simpulan dan Saran}

\subsection{Simpulan}

Dengan nilai akumulasi mobil tertinggi yaitu 251 kendaraan yang terjadi pada pukul 15.00 16.00 WIB disimpulkan bahwa satuan ruang parkir (SRP) mobil masih dapat menampung kendaraan yang parkir dan nilai akumulasi parkir kurang dari satuan ruang parkir yang tersedia yaitu 454 petak sehingga tidak perlu adanya penambahan ruang parkir

\subsection{Saran}

1) Perlu diberikan batasan-batasan parkir yang jelas seperti memberi garis- garis marka pada petak parkir sehingga kendaraan yang parkir sesuai dengan petak yang disediakan dan tidak ada kendaraan yang parkir tidak pada tempatnya.

2) Kondisi jalan dan pelataran parkir yang kurang baik dapat mempengaruhi pergantian parkir kendaraan yang akan masuk dan keluar lokasi parkir. Sehingga perlu adanya perbaikan fasilitas parkir berupa perbaikan jalan dan pelataran di areal parkir B pada Bandar Udara Internasional Kualanamu Medan agar dapat mempercepat kendaraan yang akan masuk dan meninggalkan lokasi parkir.

3) Mengoptimalkan petak parkir dengan menggunakan rentang waktu pembayaran parkir atau tarif parkir bertahap agar kendaraan yang parkir tidak menempati suatu petak parkir dalam waktu yang lama yang dapat mengurangi kapasitas areal parkir pada 
Bandar Udara Internasional Kualanamu Medan.

4) Memperbaiki sirkulasi kendaraan yang masuk dan meninggalkan lokasi parkir, sehingga pos pintu masuk hanya di pergunakan untuk kendaraan masuk ke lokasi parkir sedangkan pos pintu keluar hanya di pergunakan kendaraan yang akan meninggalkan lokasi parkir.

5) Perlu adanya penelitian lanjutan mengenai pelayanan angkutan umum yang tersedia khusus penumpang di Bandar Udara Internasional Kualanamu Medan dalam rangka mengurangi pemakaian kendaraan pribadi yang memakai lahan parkir di bandara.

\section{Daftar Pustaka}

Armulina Patihawa, Analisis kebutuhan parkir pada Bandar udara Radin Inten II Branti Lampung Selatan. Jurusan Teknik Sipil Fakultas Teknik Universitas Lampung 2014.

Dayana, E.2012. Analisis Kebutuhan Parkir Kendaraan di Bandara Husein Sastranegara. Jurnal Teknik Sipil Fakultas Teknik dan Lingkungan. Institut Teknologi Bandung. Bandung.

Departemen Perhubungan Direktur Jenderal Perhubungan Darat.1996.Pedoman

Teknis Penyelenggaraan Fasilitas Parkir.Jakarta : Departemen Perhubungan.

Mariani, Since dan Irdayanti B.2010. Karakteristik Kebutuhan Parkir Pada Hotel Bintang Tiga di Makassar. Teknik Sipil Fakultas Teknik Universitas Hasanuddin. Makassar.

Messah, Y.A, dkk.2012. Analisis Kebutuhan Lahan Parkir di Rumah Sakit Umum Daerah Prof.Dr.W.Z Johannes Kupang. Jurnal Teknik Sipil. Vol 1 No 4: Fakultas Teknik Sipil Undana

Suweda, I.W, dkk.2008. Analisis Karakteristik dan Permodelan Kebutuhan Parkir Pada Pusat Perbelanjaan di Kota Denpasar. Jurnal Ilmiah Teknik Sipil; Denpasar.

Wikrama, A.A.J.2010. Analisis Karakteristik dan Kebutuhan Parkir di Pasar Kreneng. Jurnal Ilmiah Teknik Sipil Vol 4 No 2. Fakultas Teknik.Universitas Udayana,Denpasar. 